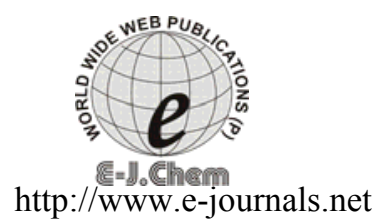

ISSN: 0973-4945; CODEN ECJHAO

E-Journal of Chemistry

2011, 8(S1), S304-S308

\title{
Spectrofluorimetric Method for the Estimation of Erlotinib Hydrochloride in Pure and Pharmaceutical Formulations
}

\author{
V.RAJESH*, V.JAGATHI, K.SINDHURI and G.DEVALA RAO \\ ${ }^{*}$ M.I.C College of Technology, Vijayawada-521180, A.P, India \\ K.V.S.R. Siddhartha College of Pharmaceutical Sciences \\ Siddhartha Nagar, Vijayawada -520 010, A.P., India \\ reachvalluru@gmail.com
}

Received 1 October 2010; Accepted 27 November 2010

\begin{abstract}
A simple and sensitive spectrofluorimetric method has been developed for the estimation of erlotinib hydrochloride in pure and pharmaceutical dosage forms. Erlotinib hydrochloride exhibits maximum fluorescence intensity in methanol and the Beer's law was obeyed in the range of $1-5 \mu \mathrm{g} / \mathrm{mL}$ at an excitation wavelength $\left(\lambda_{\mathrm{ex}}\right)$ of $295 \mathrm{~nm}$ and an emission wavelength $\left(\lambda_{\text {em }}\right)$ of $339 \mathrm{~nm}$. Stability studies with respect to time and temperature were also carried out. The results obtained were in good agreement with the labelled amounts of the marketed formulations. This method has been statistically evaluated and found to be accurate and precise.
\end{abstract}

Keywords: Erlotinib hydrochloride, Spectroflourimetry, Pharmaceutical formulations, Estimation

\section{Introduction}

Erlotinibhydrochloride (ETHC); $N$ (3-Ethynylphenyl) [6,7bis (2methoxyethoxy) quinazolin4-yl] is a drug used to treat non-small cell lung cancer, pancreatic cancer ${ }^{1}$ and several other types of cancer. It is a tyrosine kinase inhibitor ${ }^{2}$, which acts on the epidermal growth factor receptor $^{3-5}$ (EGFR). Erlotinib specifically targets the epidermal growth factor receptor ${ }^{6-7}$ (EGFR) tyrosine kinase, which is highly expressed and occasionally mutated in various forms of cancer. A few numbers of methods such as HPLC, LC-MS were reported for the estimation of erlotinib hydrochloride. Literature survey reveals that no spectrofluorimetric method has been developed for the estimation of erlotinib hydrochloride. It is soluble in water, methanol, ethanol, chloroform, 1, 4 dioxan. Its molecular weight is $429.90 \mathrm{~g} / \mathrm{mol}$. The present article reports a simple spectroflourimetric method for the estimation of erlotinib hydrochloride. 


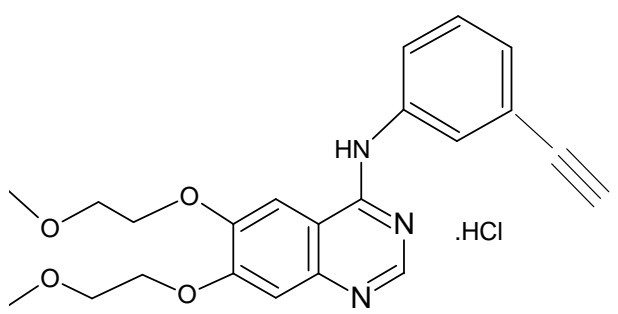

Erlotinib hydrochloride

\section{Spectrofluorimetric method}

Spectrofluorimetry has assumed a major role in drug analysis because of its greater sensitivity and selectivity than absorption spectrophotometry. Spectrophotometric technique rely upon the comparision of incident light $\left(\mathrm{I}_{0}\right)$ and transmitted light ${ }^{8}\left(\mathrm{I}_{\mathrm{t}}\right)$ intensity. At very low concentrations of absorbing species, the difference becomes extremely difficult to detect and becomes the factor, which limits the sensitivity of this technique. In spectrofluorimetry, the emitted radiation is measured at right angle to the incident beam and at longer wavelength and as the concentration of the fluorescent species ${ }^{9}$ decreases, so the intensity of the light emitted decreases.

The sensitivity arises the requirement that two wavelengths are involved the excitation wavelength and the fluorescence emission wavelength which discriminates ${ }^{10}$ it from many compounds, which do not display significant fluorescence.

The emission of light by the molecules which are excited by the absorption of visible or UV radiation is the basis of fluorescence spectroscopy. Due to relatively low cost and high analytical sensitivity, this technique is widely employed in the quantitative analysis of drugs and metabolites and in the evaluation of these substances with biological macromolecules ${ }^{11}$.

Molecular planarity and rigidity plays a significant role in the ability of a compound to fluoresce. A conjugated system of double bonds held in planar and rigid form that strongly absorbs in the $200-800 \mathrm{~nm}$ region of the electromagnetic spectrum is usually a good candidate for developing fluorescence.

\section{Experimental}

ELICO spectrofluorimeter model SL 174 was used in this experiment

\section{Reagents}

Methanol AR grade were purchased and used as it is received.

\section{Standard drug solution}

About $100 \mathrm{mg}$ of erlotinib hydrochloride was accurately weighed and dissolved in about $100 \mathrm{~mL}$ of methanol to obtain a stock solution of $1 \mathrm{mg} / \mathrm{mL}$. This solution was further diluted with methanol to obtain a working standard solution of $10 \mu \mathrm{g} / \mathrm{mL}$.

\section{Study of fluorescence spectral characteristics of erlotinib hydrochloride}

The standard solution erlotinib hydrochloride was prepared in different solvents like water, methanol, ethanol, 1, 4 dioxan and was scanned from 200-800 $\mathrm{nm}$ to find out the excitation and emission wavelengths and also to find out the best solvent in which the drug exhibits maximum fluorescence. It was found that the drug exhibits maximum fluorescence in methanol at an excitation wavelength of $295 \mathrm{~nm}$ and an emission wavelength of $339 \mathrm{~nm}$. 


\section{Preparation of calibration graph}

Erlotinib hydrochloride working standard solution of $10 \mu \mathrm{g} / \mathrm{mL}$ was prepared and accurately $1,1.5,2,2.5,3,3.5,4$ and $4.5 \mathrm{~mL}$ of the working standard solution was transferred into each of the eight $10 \mathrm{~mL}$ standard flasks and then made upto the mark with methanol. Resulting solutions have concentrations of $1,1.5,2,2.5,3,3.5,4$ and $4.5 \mu \mathrm{g} / \mathrm{mL}$. Fluorescence intensity was measured by setting the excitation wavelength at $295 \mathrm{~nm}$ and the emission wavelength at $339 \mathrm{~nm}$. The calibration curve was prepared by plotting fluorescent intensity (I) vs. concentration $(\mu \mathrm{g} / \mathrm{mL})$.

\section{Stability profile with respect to time}

Erlotinib hydrochloride standard solution $3 \mu \mathrm{g} / \mathrm{mL}$ was taken and set for time profile scan for 60 minutes with excitation wavelength $295 \mathrm{~nm}$ and emission wavelength of $339 \mathrm{~nm}$. The fluorescence intensity was almost stable through out the time (Figure 1)

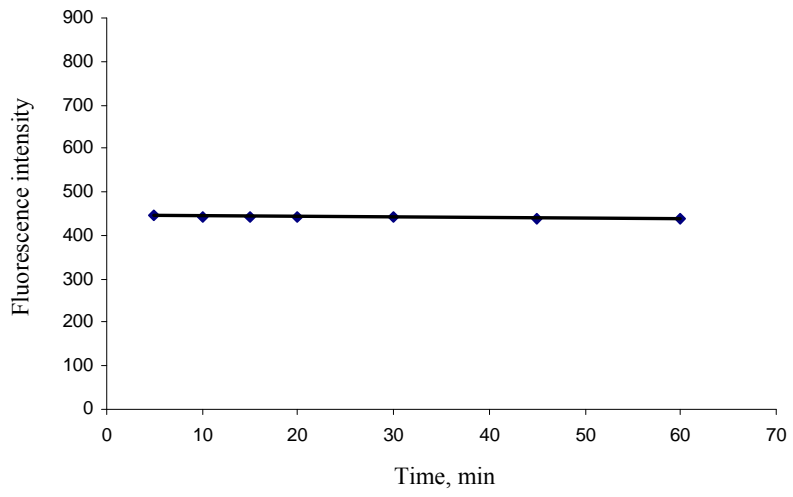

Figure 1. Effect of time on fluorescence intensity

\section{Effect of temperature on fluorescence intensity}

Erlotinib hydrochloride standard solution was $3 \mu \mathrm{g} / \mathrm{mL}$ was taken and fluorescence intensity was taken at different temperatures like $50{ }^{\circ} \mathrm{C}, 40{ }^{\circ} \mathrm{C}, 30^{\circ} \mathrm{C}$ and $25^{\circ} \mathrm{C}$. The fluorescence intensity was found to decrease with increase in temperature. (Figure 2) hence an ambient temperature $\left(25-30{ }^{\circ} \mathrm{C}\right)$ was employed during the measurement of the fluorescence intensity.

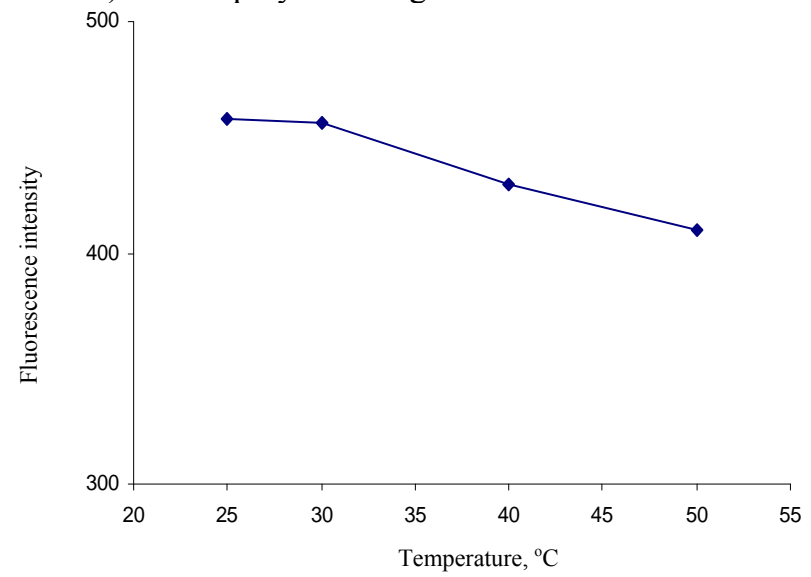

Figure 2. Effect of temperature on fluorescence intensity 


\section{Effect of $\mathrm{pH}$ on fluorescence intensity}

Erlotinib hydrochloride standard solution of $3 \mu \mathrm{g} / \mathrm{mL}$ was taken in 5 different flasks and the $\mathrm{pH}$ was adjusted to 2,4,6,8 and 10 respectively and the fluorescence intensity was measured. The data obtained was depicted in Figure 3. This shows that Erlotinib hydrochloride shows maximum fluorescence intensity at the neutral $\mathrm{pH}(6-7)$. Hence neutral $\mathrm{pH}$ is employed for determination of the fluorescence intensity of Erlotinib hydrochloride.

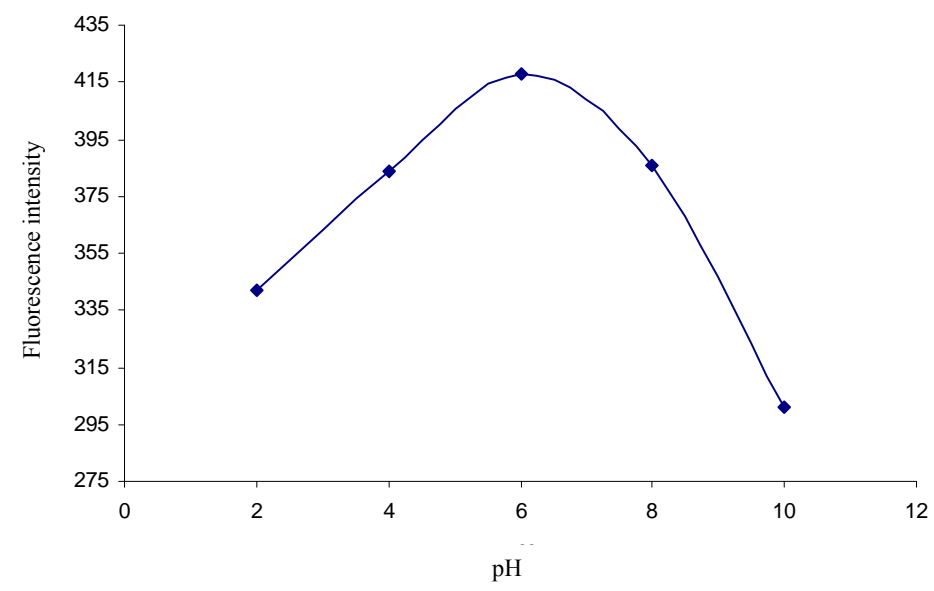

Figure 3. Effect of $\mathrm{pH}$ on fluorescence intensity

\section{Estimation of erlotinib hydrochloride in dosage forms}

Twenty tablets were taken (label claim $25 \mathrm{mg}$ of erlotinib hydrochloride /tablet) and accurately weighed. The tablets were powdered and weight equivalent to $25 \mathrm{mg}$ of erlotinib hydrochloride was weighed and dissolved in $50 \mathrm{~mL}$ of methanol and was sonicated for a period of 20 minutes. The solution was filtered through a Whatmann No.1 filter paper. The volume was made upto the mark and was suitably diluted so as to contain an equivalent to $10 \mu \mathrm{g} / \mathrm{mL}$ of erlotinib hydrochloride in the solution. Then suitable concentrations were taken and were analyzed. Similarly dilutions were prepared for erlotinib hydrochloride tablets of labeled claim $100 \mathrm{mg}$ and were analyzed. The assay values obtained were found to be within the limits.

\section{Results and Discussion}

The fluorescent characteristics such as excitation and emission wavelength of erlotinib hydrochloride were studied ( 295 and $339 \mathrm{~nm}$ respectively). The calibration curve was linear in the range of $1-5 \mu \mathrm{g} / \mathrm{mL}$ with a correlation coefficient of 0.999 . All the validation parameters are presented in Table 1 . The stability of the fluorescence intensity was found to be optimum for a period of 60 minutes. It was seen that the experiment can be done at room temperature and the fluorescent intensity was constant between $25-30{ }^{\circ} \mathrm{C}$. Also the fluorescence intensity was found to be maximum at the neutral $\mathrm{pH}$ of 6-7.

To evaluate accuracy of the method known amounts of the pure drug was added to previously analyzed samples and the mixtures were analyzed by the proposed method. The values are presented in Table 2. The accuracy values were found to be within the prescribed limits thus indicating that there is no interference of other ingredients present in the formulation. 
Table 1. Validation report for estimation of erlotinib hydrochloride

\begin{tabular}{cc}
\hline Parameters & Results \\
\hline Linearity range, $\mu \mathrm{g} / \mathrm{mL}$ & $1-5$ \\
Slope & 117.22 \\
SE of slope & 0.985 \\
Confidence limit of slope (At 95\%) & 1.446 \\
Intercept $^{*}$ & 87.78 \\
SE of intercept & 2.193 \\
Confidence limit of intercept (At 95\%) & 4.596 \\
Correlation coefficient (r) ${ }^{*}$ & 0.9999 \\
SE of r & 0.055 \\
Intraday precision ${ }^{*} \%$ & 0.73 \\
Interday precision, \% & 1.07 \\
LOD, $\mu \mathrm{g} / \mathrm{ml}$ & 0.138 \\
LOQ, $\mu \mathrm{g} / \mathrm{ml}$ & 0.419 \\
*Average of six determinations &
\end{tabular}

Table 2. Estimation of erlotinib hydrochloride in pharmaceutical formulations

\begin{tabular}{cccc}
\hline Formulation & $\begin{array}{c}\text { Labeled amount, } \\
\text { mg }\end{array}$ & $\begin{array}{c}\text { Amount found by } \\
\text { proposed method }\end{array}$ & $\begin{array}{c}\text { \% recovery } \\
\text { proposed method }\end{array}$ \\
\hline Tablet 1 & 25 & 24.56 & 98.86 \\
Tablet 2 & 25 & 24.54 & 98.75 \\
Tablet 3 & 100 & 98.78 & 99.64 \\
Tablet 4 & 100 & 99.6 & 99.79 \\
\hline
\end{tabular}

*Average of six determinations, ${ }^{* *}$ Recovery of amount added to the pharmaceutical formulation (Average of three determinations at three different levels)

\section{Conclusion}

The results indicate that the method proposed was simple, selective and rapid with reasonable precision and accuracy. Hence this method can be employed for the routine analysis of Erlotinib hydrochloride in pure form and in its formulations.

\section{Acknowledgment}

The authors are thankful to K.V.S.R.Siddhartha College of Pharmaceutical Sciences for providing the necessary facilities and my friends for their cheerful support during my course of work.

\section{References}

1. Martindale, The Extra Pharmacopeia, $31^{\text {st }}$ Edition, Reynolds J E F, (Ed) Royal Pharmaceutical Society, London, U.K, 2002, 465.

2. Alasbaster A V, Life Sci. ,1997, 60, 1053-1060

3. Quinn P, McIntyre P, Miner W D and Wallis R M, Br J Pharm., 1996, 119, 198.

4. $\quad \mathrm{Li} Z$ Z, Xu M, Xing S, Ho W, Ishii T, Li Q, Fu X and Zhao Z, J Biol Chem., 2007, 282, 3428-3432.

5. Kapil R, Dhawan S and Bhupinder Singh, IJPS., 2009, 71( 5), 585-589

6. Ross P.D and Subramanian S, Biochem., 1981, 20, 3096-3102.

7. Shohrati M, Rouini M R, Mojtahedzadeh M and Firouzabadi M, DARU, 2007, 15(1), 34-40.

8. Valeur. B, Molecular Fluorescence: Principles and Application, Wiley Press, New York, 2001, 250.

9. Hu Y.J, Liu Y, Pi Z.B and Qu S.S, Bioorg Med Chem., 2005, 13, 6609-6614.

10. Miller J.C and Miller J.N, Statistics for analytical chemistry, $2^{\text {nd }}$ Edition, Chichester, UK:Ellis Horwood, 1992, 127- 129.

11. Capka V, Yan X.U and Chen Y.H, J Pharm Biomed Anal., 1999, 21(3), 507-517. 


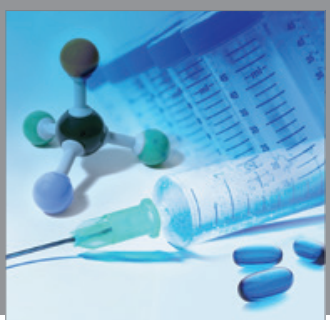

International Journal of

Medicinal Chemistry

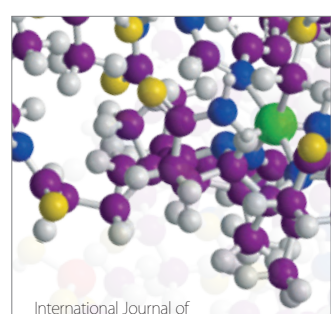

Carbohydrate Chemistry

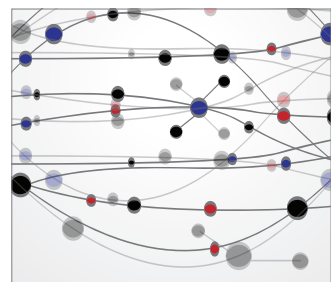

The Scientific World Journal
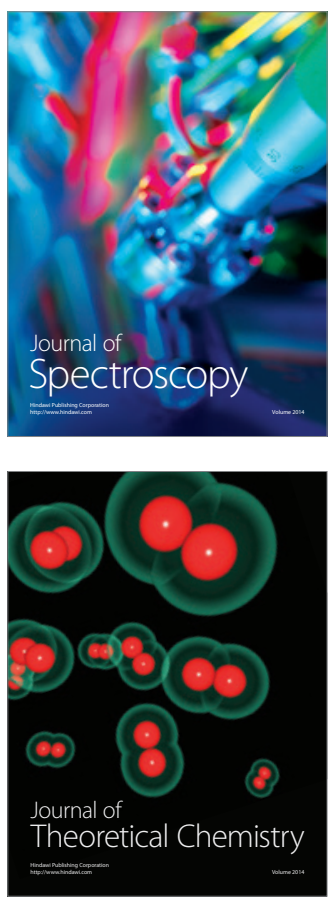
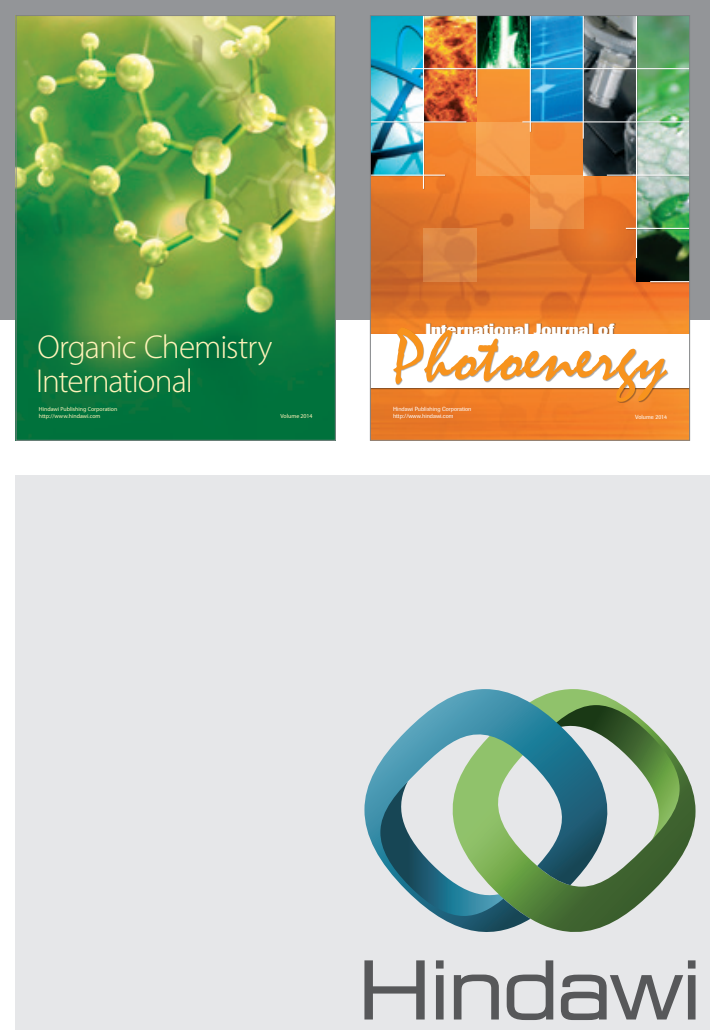

Submit your manuscripts at

http://www.hindawi.com
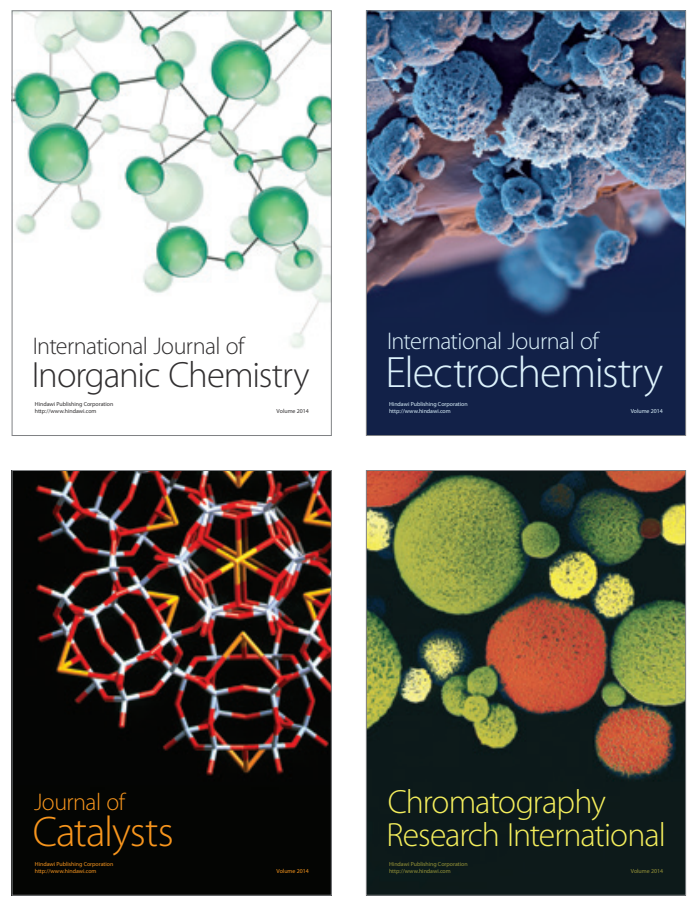
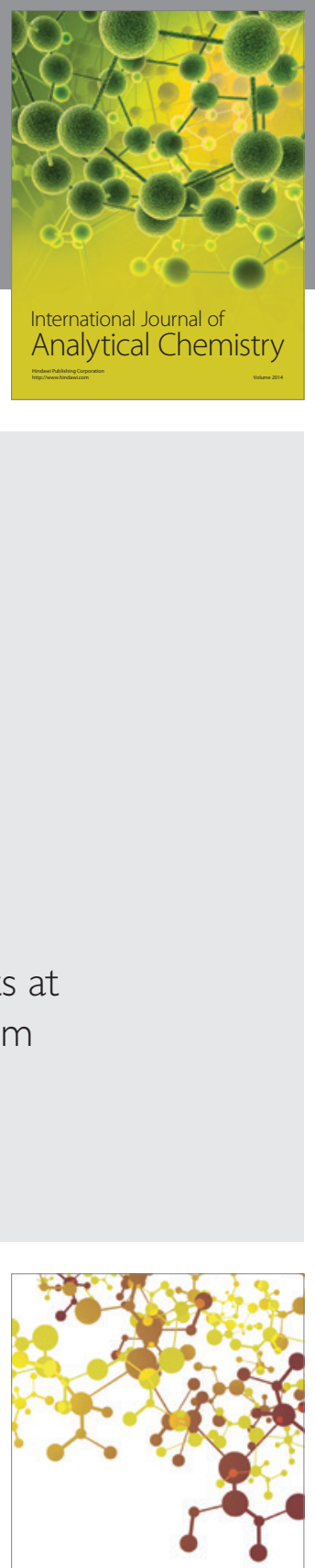

Journal of

Applied Chemistry
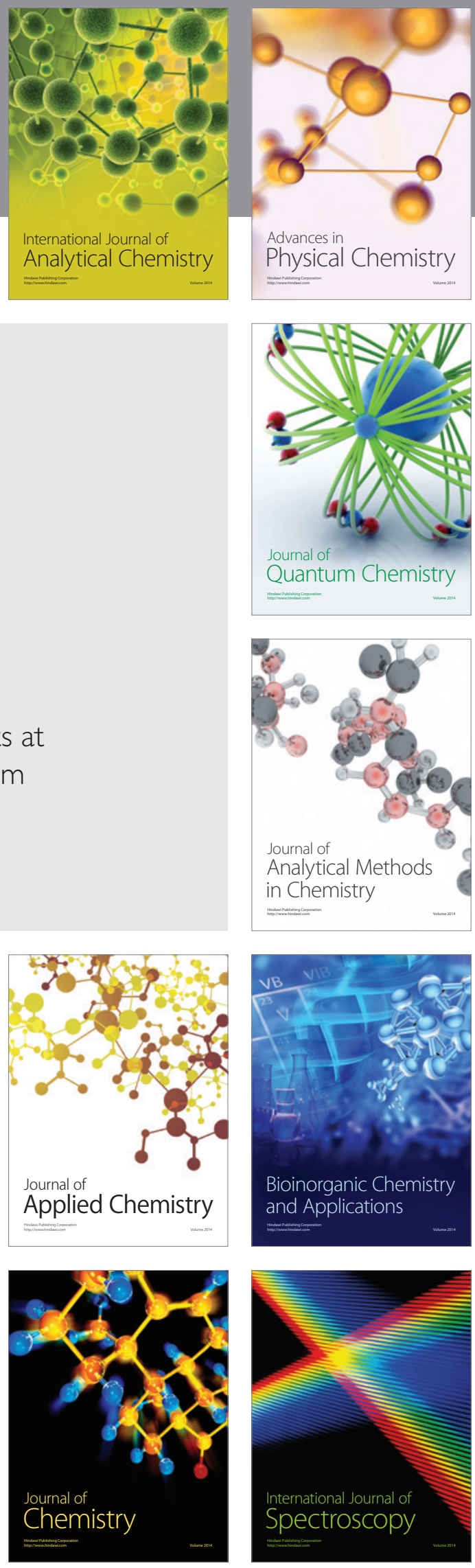